Supplement of Atmos. Chem. Phys., 19, 14585-14606, 2019

https://doi.org/10.5194/acp-19-14585-2019-supplement

(c) Author(s) 2019. This work is distributed under

the Creative Commons Attribution 4.0 License.

(c) (1)
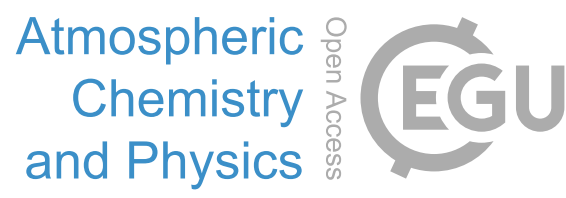

Supplement of

\title{
Constraining global aerosol emissions using POLDER/PARASOL satellite remote sensing observations
}

\section{Cheng Chen et al.}

Correspondence to: Cheng Chen (cheng.chen@univ-lille.fr) and Oleg Dubovik (oleg.dubovik@univ-lille.fr)

The copyright of individual parts of the supplement might differ from the CC BY 4.0 License. 

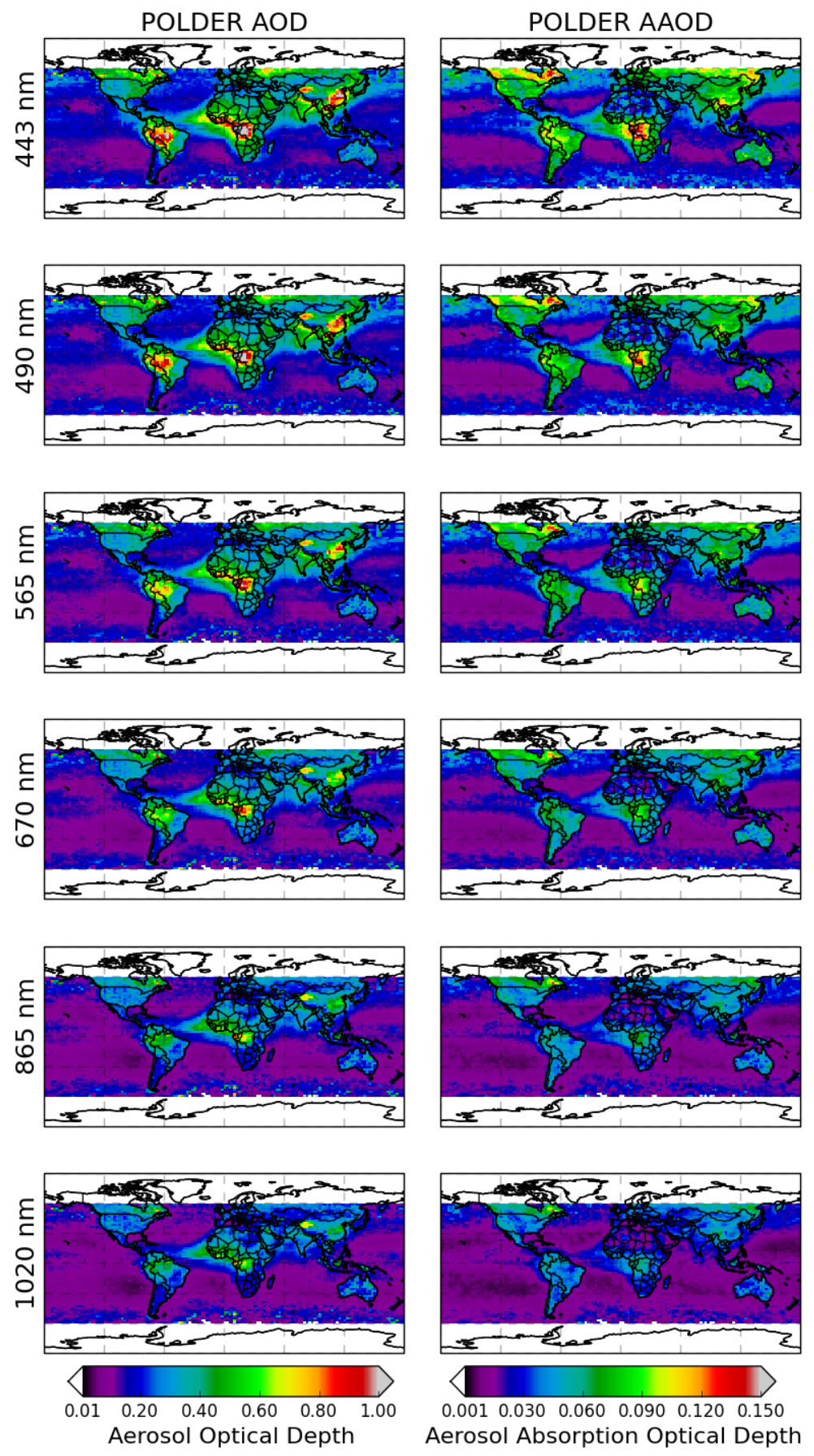

Figure S1. Global distribution of PARASOL/GRASP $2^{\circ} \times 2.5^{\circ}$ spectral AOD and AAOD at 443, 490, 565, 670, 865 and 1020 nm in year 2010 

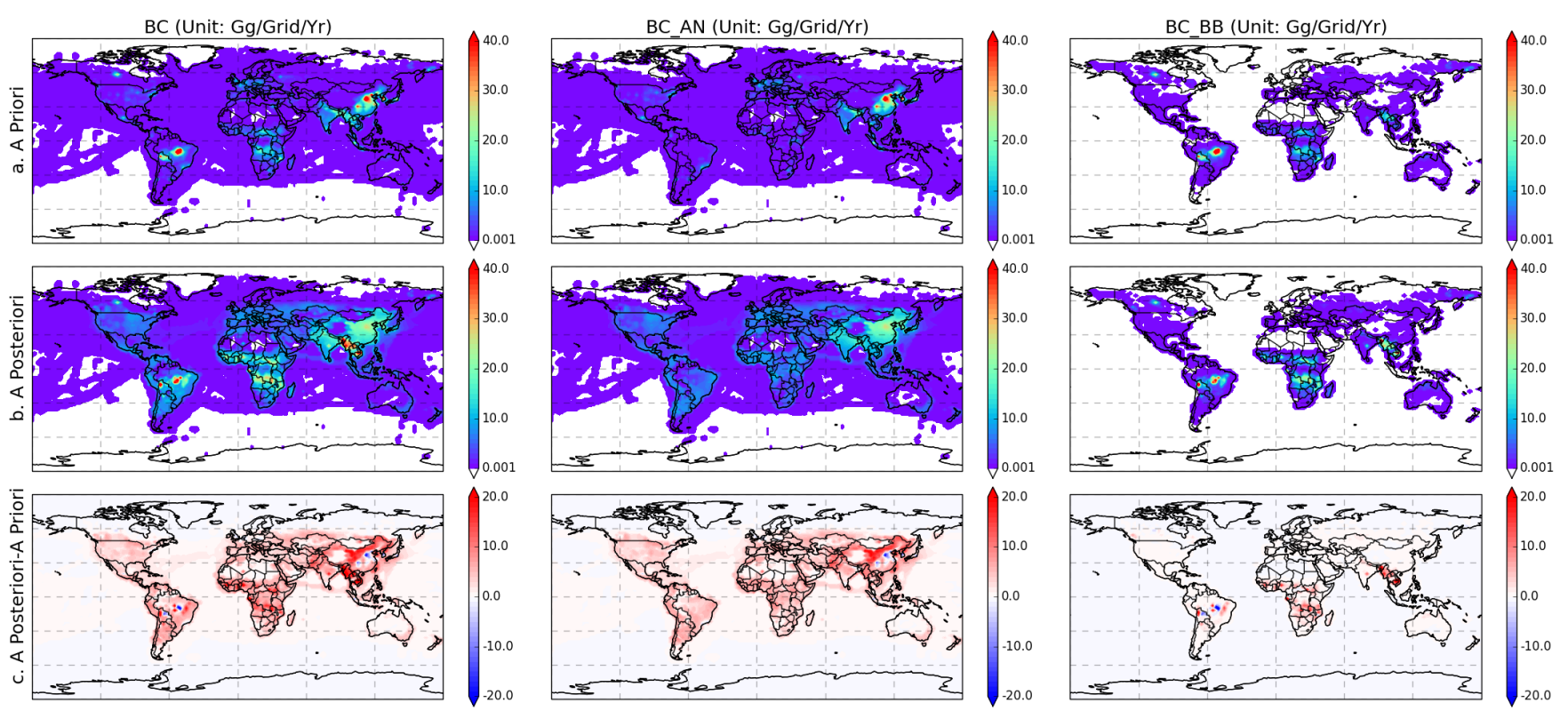

Figure S2. Global distribution of BC emissions in 2010 for total BC (left panel), anthropogenic BC (middle panel) and biomass burning BC (right panel) based on (a) a priori and (b) a posteriori emission datasets; and the differences between a posteriori and a priori emission datasets (c)
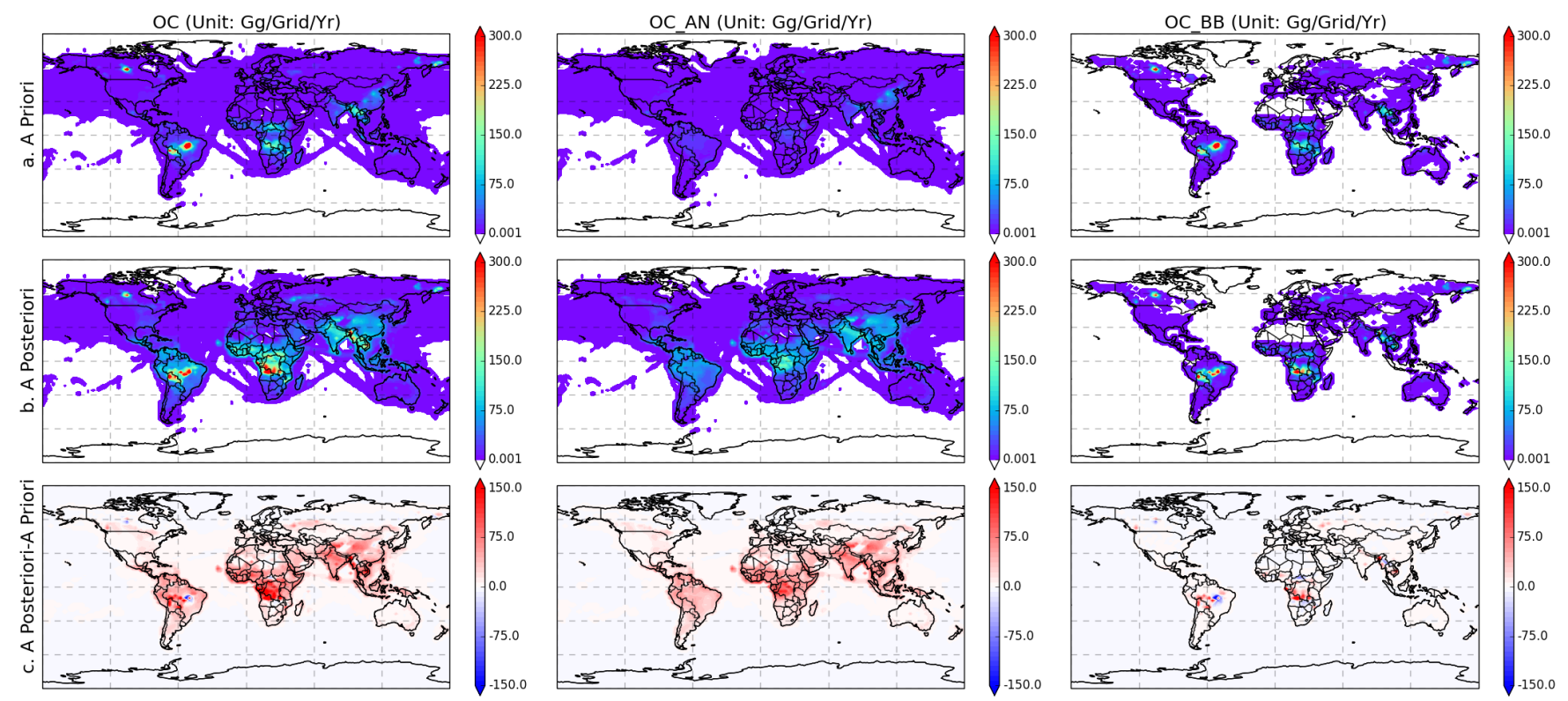

Figure S3. Same as Figure S2, but for OC 

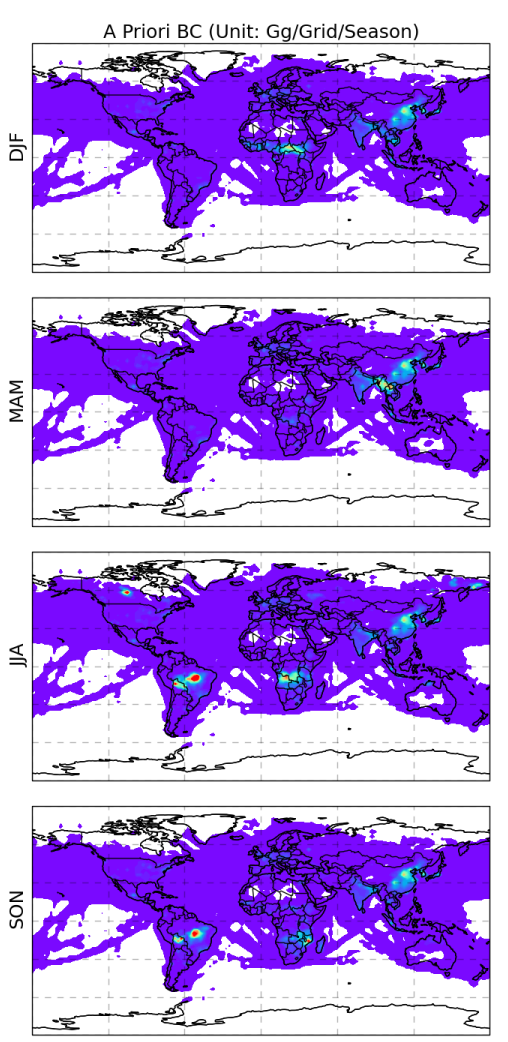
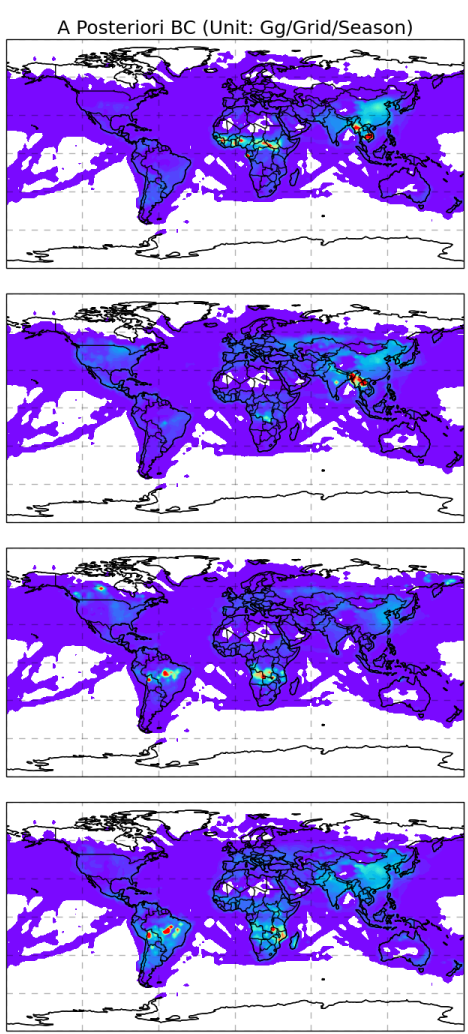
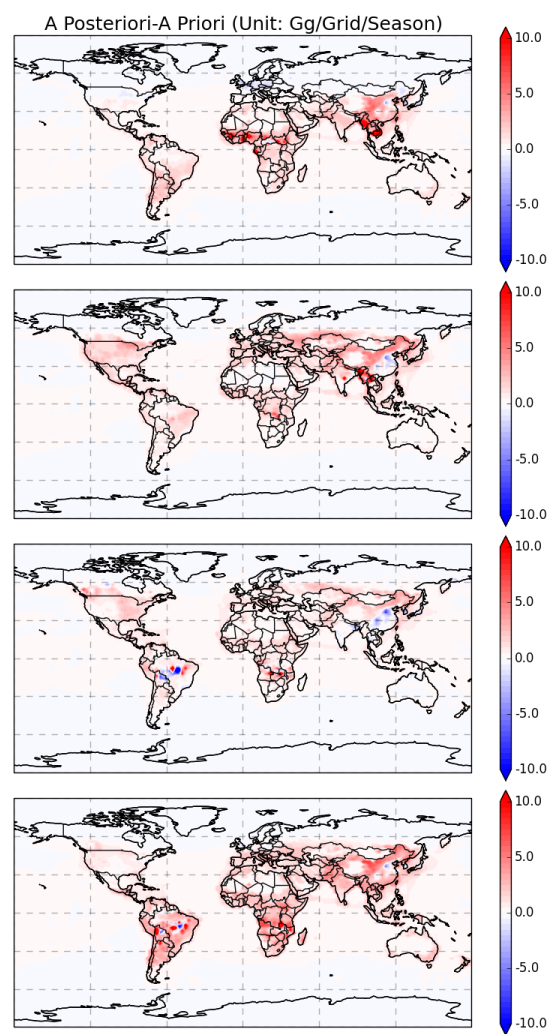

Figure S4. Global distribution of seasonal BC emission flux in year 2010 from a priori (left) and a posteriori (middle) emission datasets, and the difference between a posteriori and a priori emissions (right)
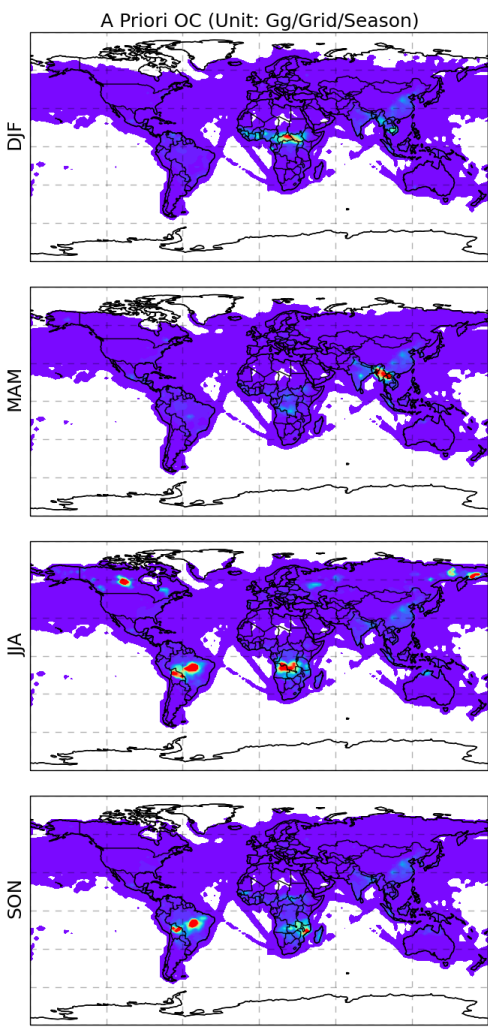
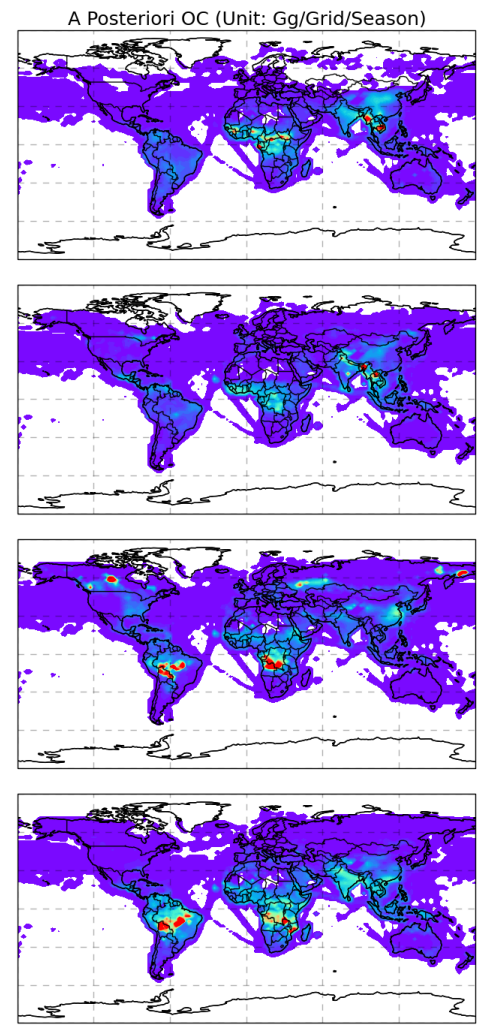
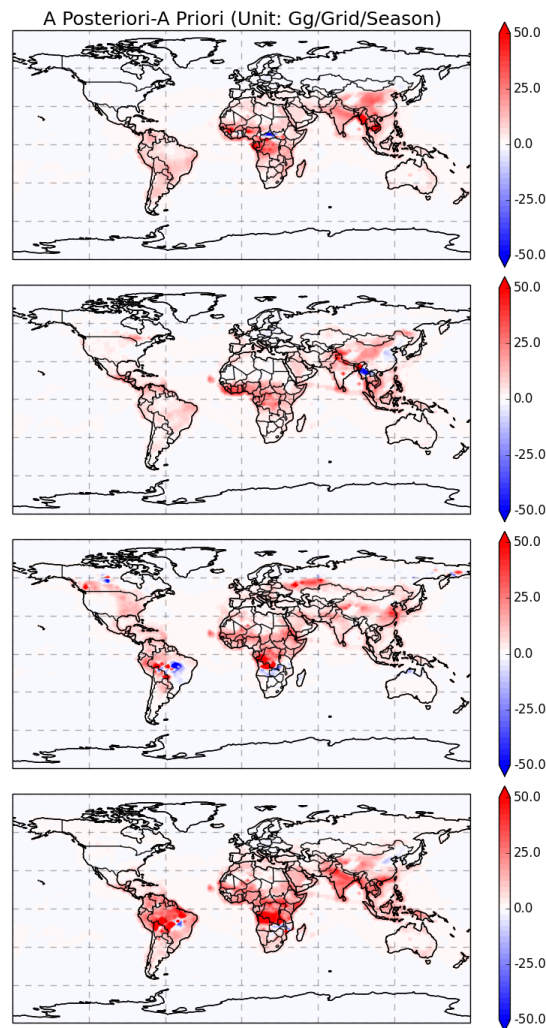

Figure S5. Same as Figure S4, but for OC 

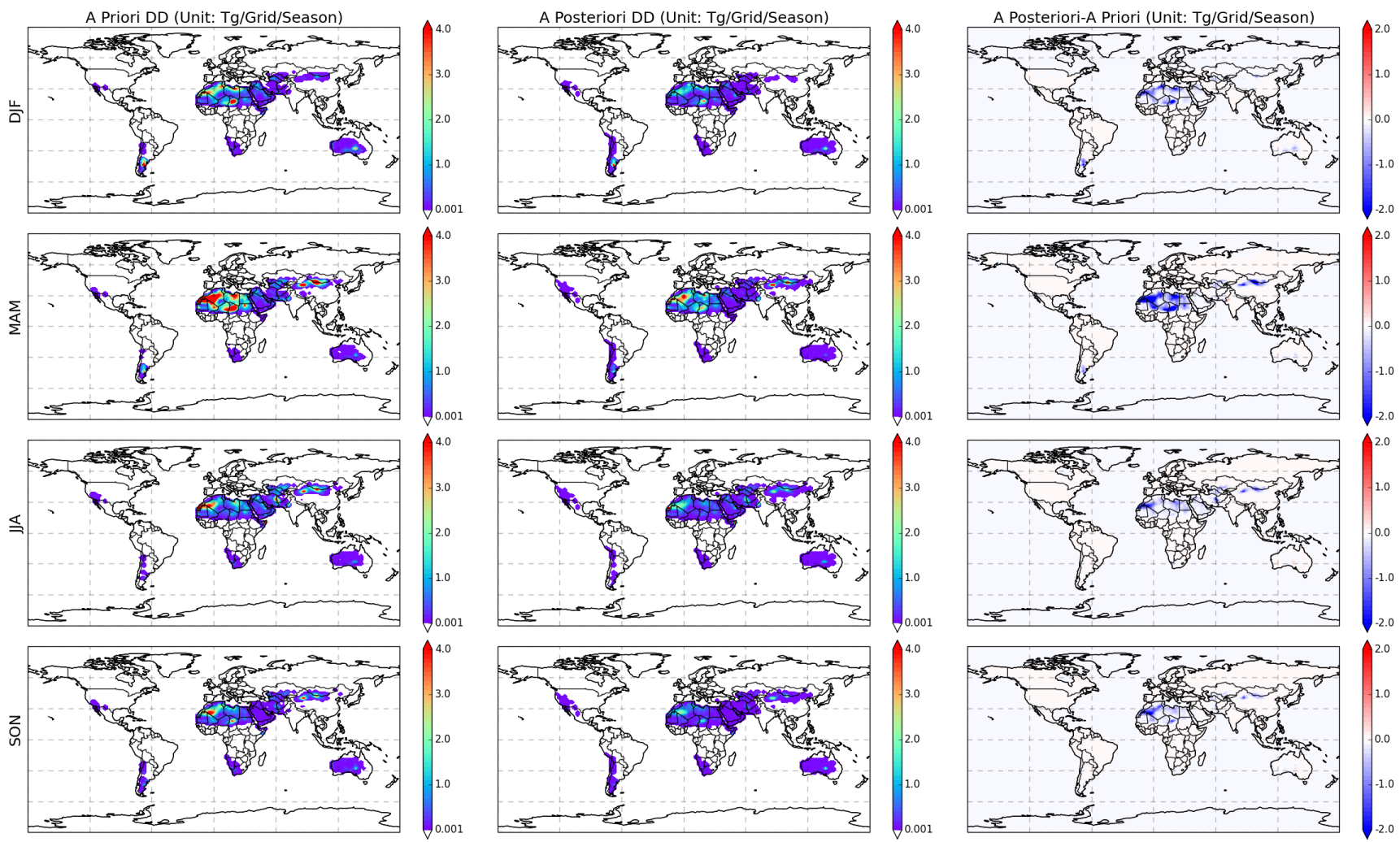

Figure S6. Same as Figure S4, but for DD 